\title{
Proceeding
}

Supplementary Issue: Spring Conferences of Sports Science. Costa Blanca Sports Science Events, 14-15 June 2019. Alicante, Spain.

\section{Multilateral training improves body image perception in female adolescents}

\author{
FRANCESCA LATINO, GIANPIERO GRECO, FRANCESCO FISCHETTI , STEFANIA CATALDI \\ Department of Basic Medical Sciences, Neuroscience and Sense Organs, School of Medicine, University of \\ Study of Bari, Italy
}

\begin{abstract}
Body image is closely linked to psychological well-being during adolescence. Physical activity is effective for improving body image disturbance and to date limited body image intervention were undertaken through physical education. Therefore, the aim of this randomized controlled study was to investigate the effects of an 8-week multilateral training on body-image satisfaction and body-size perception. 50 female students, aged 14-15 years, were assigned to experimental group $(n=25)$ that performed an extracurricular multilateral training program (90 min., 2 days a week) including cardiovascular endurance, agility, dynamic strength, flexibility, and team-building activities, or control group $(n=25)$. At baseline and after 8-week, anthropometrics and the degree of personal satisfaction towards their body were measured by body weight, Body uneasiness test (BUT) and Contour drawing rating scale (CDRS), respectively. After multilateral training, experimental group showed significant improvements $(p<0.05)$ in body weight, BUT and CDRS scores. Control group showed no significant changes. Findings suggest that an extracurricular multilateral training program could increase the body image satisfaction and improve the body-size perception in girls. Thus, extracurricular activities such as multilateral training should be considered by physical educators. Keywords: Physical activity; Girls; Physical education; Body uneasiness.

\section{Cite this article as:}

Latino, F., Greco, G., Fischetti, F., \& Cataldi, S. (2019). Multilateral training improves body image perception in female adolescents. Journal of Human Sport and Exercise, 14(4proc), S927-S936. doi:https://doi.org/10.14198/ihse.2019.14.Proc4.55

\footnotetext{
Corresponding author. Department of Basic Medical Sciences, Neuroscience and Sense Organs, School of Medicine, University of Study of Bari, Lungomare Starita 1, 70123 Bari (BA). Italy. https://orcid.org/0000-0001-8616-5372

E-mail: francesco.fischetti@uniba.it

Supplementary Issue: Spring Conferences of Sports Science. Costa Blanca Sports Science Events, 14-15 June 2019. Alicante, Spain.

JOURNAL OF HUMAN SPORT \& EXERCISE ISSN 1988-5202

(c) Faculty of Education. University of Alicante

doi:10.14198/jhse.2019.14.Proc4.55
} 


\section{INTRODUCTION}

Body image is the dynamic perception of one's body-how it looks, feels, and moves. It can change with mood, physical experience, and environment (Croll, 2005). There are many different factors affecting body image, including gender, media, parental relationships and puberty, as well as weight and popularity (Graham, Eich, Kephart, \& Peterson, 2000). Body image is closely linked to psychological well-being during adolescence and can have harmful effects when a child is dissatisfied with her body. Furthermore, the importance of bodyimage dissatisfaction is growing due to its implication as a risk factor for the development of eating disorders, depression, emotional distress, low self-esteem, appearance rumination and unnecessary cosmetic surgery (Lawler \& Nixon, 2011; Ruble, Martin, \& Berenbaum, 2006). Adolescents experience significant physical changes in their bodies during puberty and are likely to experience highly dynamic perceptions of their body image. Puberty for girls brings with it characteristics that are often perceived as less laudable, as girls generally get rounder and gain body fat. These changes can serve to increase girls' body dissatisfaction (Bearman, Presnell, Martinez, \& Stice, 2006; Croll, 2005). In Western society, the ideal body for females is a thin body is viewed as more desirable. The preference toward thinness appears to increase as girls develop from childhood to adolescence (Wertheim \& Paxton, 2011).

Physical education is a subject in which the body is a focus of curricular learning outcomes and so could be construed as a school site that presents risks for the development of body image disturbance, as well as opportunities for the development of positive body image. For example, engaging in more physical activity is associated with lower body image disturbance (Neumark-Sztainer, Goeden, Story, \& Wall, 2004). In this regard, physical education engagement could be used to enhance body image. On the other hand, physical education presents stimuli and cues which have the potential to trigger body image disturbance ( $O$ ' Donovan \& Kirk, 2008). Thus, the school is widely recognized as an important institution may promote physical and psychological well-being. In fact, young people that are sufficiently active enjoy better physical health (Catuzzo et al., 2016; Lubans, Morgan, Cliff, Barnett, \& Okely, 2010) and report more positive physical selfconcept and global self-esteem (Dishman et al., 2006). However, the physical activity levels of the adolescents are currently insufficient to promote these benefits (Hardy, King, Espinel, Cosgrove, \& Bauman, 2010; Sallis, 2000). In addition, school-based interventions in promoting physical activity, fitness and lifestyle in adolescents result in an inconclusive picture (Russ, Webster, Beets, \& Phillips, 2015). Therefore, it becomes very important to recommend an extracurricular physical activity (Crouter, Salas, \& Wiecha 2016; Li et al., 2014), which already showed significant effects in improving physical fitness in people, performed with a multilateral approach (Fischetti, Cataldi, Di Terlizzi, \& Greco, 2019; Fischetti, Cataldi, \& Greco, 2019; Fischetti \& Greco, 2017; Greco, Cataldi, \& Fischetti, 2019). However, few studies have evaluated physical activity interventions outside of the school setting (Mears \& Jago, 2016; Van Sluijs, McMinn, \& Griffin, 2007).

Although a meta-analysis has confirmed the effectiveness of physical activity for ameliorating body image disturbance (Campbell \& Hausenblaus, 2009), to date limited body image intervention work has been undertaken through physical education (Burgess, Grogan, \& Burwitz, 2006; O'Brien, Ginis, \& Kirk, 2008). However, these studies provide some preliminary evidence for the effectiveness of physical education as a vehicle through which to deliver body image interventions, through the promotion of competence enhancing activities. Therefore, with this background knowledge, we designed a randomized controlled after-school intervention study aimed to investigate the effects of a multilateral training program on body-image perceived by girls. We hypothesized that an 8-week intervention would significantly increase the body image satisfaction and improve body-size perception. 


\section{MATERIALS AND METHODS}

\section{Study design}

This research was developed through a randomized controlled study design in order to collect the data from anthropometric measures (i.e., body weight) and two standardized psychological tests (i.e., Body Uneasiness Test and Contour drawing rating scale) and compare the same group at different times with respect to the measured dependent variables. Data were collected and recorded at baseline (Pre-test) and after 8weeks (Post-test).

\section{Participants}

Fifty female adolescent students aged 14-15 years, with the same socio-economic background of origin, attending the first year of high school, were recruited to participate in the study and were pair-matched based on body weight and then randomly allocated into 2 groups: experimental group ( $n=25$; age $14.3 \pm 0.5$ years; body height $159.5 \pm 6.4 \mathrm{~cm}$; body weight $64.1 \pm 9.7 \mathrm{~kg}$ ) that performed an extracurricular multilateral training program or control group ( $n=25$; age $14.4 \pm 0.5$ years; body height $157.8 \pm 5.4 \mathrm{~cm}$; body weight $61.9 \pm 6.6$ $\mathrm{kg}$ ). An a priori power analysis (Faul, Erdfelder, Lang, \& Buchner, 2007) with an assumed type lerror of 0.05 and a type II error rate of 0.20 (80\% statistical power) was calculated and revealed that 15 participants per group would be sufficient to observe medium effects. However, to avoid the experimental mortality, that is the loss of subjects that could threaten the validity of the research design, more subjects were recruited. Participants were informed of the possible benefits of study participation. No additional incentives for participation were provided, and there was no cost to participate in the study. Participants were excluded if they had a chronic paediatric disease or had an orthopaedic condition that would limit their ability to perform exercise. All participants and their parents received a complete explanation in advance about the purpose of the experiment, its contents, and safety issues based on the Declaration of Helsinki, and the parents provided their informed consent. The study was conducted from February to March 2019 and all participants completed the study.

\section{Procedures and measures}

First, during the physical education lesson the anthropometric measurements were collected. Body height (in $\mathrm{cm}$ to the nearest $0.1 \mathrm{~cm}$ ) was measured using a SECA® stadiometer, and body weight (in $\mathrm{kg}$ to the nearest $0.1 \mathrm{~kg}$ ) was measured using Tanita® digital scales. The participants were barefooted and wore light clothing during the measurements. The body weight was used as dependent variable because the BMI could decrease after 8 weeks of intervention for the possible height growth of the participants.

Next, participants were asked to complete two standardized psychological tests to assess the degree of personal satisfaction towards their body. Specifically, we used the Body Uneasiness Test (BUT) (Cuzzolaro, Vetrone, Marano, \& Battacchi, 1999) and Contour drawing rating scale (CDRS) (Thompson \& Gray, 1995; Wertheim, Paxton, \& Tilgner, 2004).

The BUT is a self-administered questionnaire specifically designed to explore several areas in clinical and non-clinical populations: (1) dissatisfaction regarding the body and its weight, (2) avoiding and compulsive control behaviour, (3) experience of separation and extraneity regarding the body, and (4) specific worries about certain body parts, characteristics or functions. The term 'uneasiness' seemed particularly adapted to express the complex idea of dissatisfaction which also includes malaise, embarrassment, anxiety, doubt, suspicion, trepidation, worry, mistrust, and misgiving. Participants were asked to rate 34 different body experiences (BUT-A) and 37 body parts (BUT-B) on a 6-point Likert-type scale (from 'never' to 'always'), indicating how often they happen to dislike each experience or part of their body. Higher scores indicate 
greater body uneasiness. BUT scores were analysed considering the mean intensity of the dislike of all disliked body parts, allowing to assess the dissatisfaction with one's own body image. In this study the BUT showed a high reliability and internal consistency (Cronbach's $\alpha=0.86$ ).

The CDRS is a valid measure of body-size perception and allows to measure body image in a reliable and simple way. In this research, participants rated current and ideal figure sizes on the CDRS, which includes nine figures, rated 1-9 figural stimuli (often called "silhouettes"). These figural stimuli start from a very thin figure (indicated with 1) and increase in size as they approach an obese figure (indicated with 9) (see Figure 1). Participants were asked to rate their current size (real figure) and their ideal figure. In this study, instructions for current figure were to circle the number on the line "closest to your present size. That is, the size you are at the moment". Phrasing for ideal size was "closest to the size you would like to be". Current versus ideal size discrepancy (current-ideal) was also calculated and used as an indicator of bodily dissatisfaction in terms of distance from an ideal of beauty. A discrepancy $=0$ indicates that the subject is satisfied with his body image; a discrepancy between 1-4 indicates that the subject is little satisfied with his body image; a discrepancy $\geq 5$ indicates that the subject is highly dissatisfied with his body image.

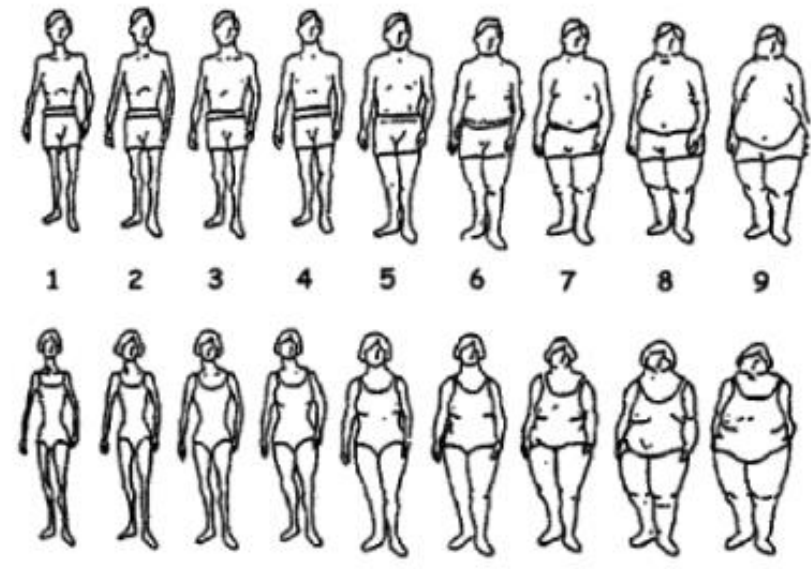

Figure 1. Contour drawing rating scale.

\section{Multilateral training program}

The multilateral approach respects the physiologic age and psychological maturation of youth and is a means to improve fitness (Bompa \& Buzzichelli, 2018). In the study, the participants allocated to the intervention group underwent an extracurricular multilateral program for a period of 90 minutes, two days a week, with a total of 16 training sessions. The entire intervention program was implemented in 8 weeks from the beginning of February until March 2019. The multilateral training program was supervised and conducted by two graduates in physical education to ensure safety, proper intensity, and appropriate exercise technique (Greco, Settimo \& Fischetti, 2018). Each training sessions started with a brief dynamic warm-up program mainly consisting of callisthenic-type exercises for 10 minutes and ended with a 10-minute cool-down program consisting of static stretching exercises. The targeted components of the multilateral training program included cardiovascular endurance, agility, dynamic strength, flexibility, and team-building activities.

The dynamic warm-up included arm swings, trunk twisting, high marching, stride jumping, high knees, side bending, side stretching, skipping leg swings, backward sprinting, and lateral shuffles. 
The cool-down included traditional movements such calf stretches, quadriceps stretches, back stretches, straddle stretches and groin stretches.

Cardiovascular endurance consisted of a variety of training exercises, including running, walking, circuits, sprint intervals and agility (i.e., the ladder exercise), performed gradually from 20 to 30 minutes. This training program was incorporated into every training session.

Dynamic strength included resistance training and body weight plyometrics such as jump squats, lunges, push-ups, pull-ups, curl-ups, half squats, long jumps, planks and medicine ball tosses. This program began with 1-2 set of 8-15 repetitions with $45 \mathrm{sec}$ of slow walking between each exercise and adequate exercises to include all major muscle groups. In addition, this training program was included into every session and lasted 10 to 20 minutes.

Flexibility was trained using both dynamic and static stretches, typically as a part of the warm-up or cooldown phase of each training session.

The team-building activities of the training program consisted of team games such as volleyball, basketball, handball and soccer. The adolescents also played modified forms of these sports. The activities were characterized by a predominantly playful approach to encourage enthusiasm, socialization and participation of the young students. These activities were performed at the end of the session, before the cool-down.

\section{Statistical analysis}

SAS JMP® Statistics (Version <14.1>, SAS Institute Inc., Cary, NC, USA, 2018) was used for all analysis and the data were presented as group mean values and standard deviations. Normality of all variables was tested using Shapiro-Wilk test procedure. At baseline, to detect differences between the study groups in the anthropometric and psychological data the one-way ANOVA and the Mann-Whitney $U$ test were used, respectively. A paired t-test was used to compare changes over 8 weeks in the same group concerning the body weight. The distribution of the BUT and CDRS scores was not normal (Shapiro-Wilk test: $p<0.05$ ); therefore, a nonparametric Wilcoxon signed-rank test was used to identify the significant changes within the groups in the psychological test scores after 8-week of training.

The effect size was identified to provide a more qualitative interpretation of the extent to which changes observed were meaningful. Cohen's $d$ was calculated as post-training mean minus pre-training mean divided by pooled SD before and after training, and interpreted as small, moderate and large effects defined as 0.20 , 0.50 , and 0.80, respectively (Cohen, 1992). For nonparametric data, effect size was calculated using this formula $r=\mathrm{Z} / \sqrt{\mathrm{N}}$ and interpreted as small, moderate and large effects defined as $0.10,0.30$, and 0.50 , respectively (Cohen, 1992). The standardized Cronbach's alpha coefficient (Cohen et al., 2011) was used as a measure of reliability of the standardized psychological tests. Statistical significance was set at $p \leq 0.05$.

\section{RESULTS}

All participants received the treatment conditions as allocated and completed the training program, without anyone having reported any training-related injury. Both groups did not differ significantly at baseline in age, anthropometric characteristics, as well as in psychological measures $(p>0.05)$. Pre- and post- intervention results for all dependent measures are presented in Table 1. 
Table 1. Changes over 8-week in body weight, BUT and CDRS scores. Data are mean $( \pm S D)$

Multilateral training group Control group

$(n=25)$ $(n=25)$

\begin{tabular}{lcccccc}
\hline Variables & Pre-test & Post-test & $\boldsymbol{\Delta}$ & Pre-test & Post-test & $\boldsymbol{\Delta}$ \\
\hline Body weight $(\mathrm{kg})$ & $64.1(9.7)$ & $62.6(9.4)^{*}$ & $-1.5(2.2)$ & $61.9(6.6)$ & $62.2(6.3)$ & $0.4(1.2)$ \\
Body Uneasiness Test & $3.7(1.3)$ & $2.9(1.4)^{*}$ & $-0.8(1.6)$ & $3.5(0.8)$ & $3.4(1.0)$ & $-0.1(1.2)$ \\
Contour drawing rating scale & $5.0(3.1)$ & $3.3(3.3)^{*}$ & $-1.6(4.0)$ & $4.8(1.3)$ & $4.6(1.1)$ & $-0.2(0.9)$ \\
\hline
\end{tabular}

Note: values are presented as mean ( \pm SD); $\Delta$ : pre-post mean difference; Paired t-test and Wilcoxon signed-rank test were used to compare changes for body weight and psychological test scores, respectively. ${ }^{*}$ Significantly different from pre-test $(p<0.05)$.

Body weight. Paired t-test showed that body weight significantly decreased in the experimental group ( $\mathrm{t}(24)$ $=-3.35, p<0.01, d=0.64)$ over 8 weeks. No significant differences were found in the control group $(p>$ 0.05).

Body uneasiness test. Nonparametric Wilcoxon signed-rank test detected significantly lower scores in the experimental group ( $S=-73.5, p<0.05, r=0.31$ ) after intervention program. Also, no significant difference was observed in the control group $(p>0.05)$.

Contour drawing rating scale. Nonparametric Wilcoxon signed-rank test found that the values of the discrepancy between the current versus ideal size in the CDRS were significantly lower in the experimental group ( $S=-67.5, p<0.05, r=0.26)$, whereas no significant differences were found in the control group $(p>$ $0.05)$ after 8 weeks.

\section{DISCUSSION}

The present study was designed to test the hypothesis that participation in 8 weeks of extracurricular multilateral training would significantly increase the body image satisfaction and improve body-size perception in 14-15-year-old female adolescents. In accordance with this hypothesis, the results revealed that participation in an extracurricular physical education intervention with a multilateral approach, including cardiovascular endurance, agility, dynamic strength, flexibility, and team-building activities, may increase the satisfaction with their bodies in girls.

The benefit of multilateral approach was substantial in girls and this confirms that general physical activity could be associated with positive appearance (Fischetti, Latino, Cataldi, \& Greco, 2019; Henry, Anshel, \& Michael, 2006). However, it is demonstrated that girls involved in team sports report a more positive body image than girls engaged in general physical activity (Jaffee \& Lutter, 1995) and non-sports physical activity is associated with high body shame (Parsons \& Betz, 2001). In present study, likely, improvement in body image dissatisfaction was due to the additive effect of this multilateral approach. In fact, the intervention program consisted in exercises aimed to develop of the conditional and coordinative motor abilities, and in team games.

In this study, weight changes may have affected the perception of one's body in girls. In fact, the dissatisfaction of the girls' body was a function of body weight: weight loss reported greater body satisfaction in girls (Austin, Haines, \& Veugelers, 2009; Kostanski, Fisher, \& Gullone, 2004; Mäkinen, Puukko-Viertomies, Lindberg, Siimes, \& Aalberg, 2012; Presnell, Bearman, \& Stice, 2004). The results of the study highlighted the effectiveness of the physical activity in reducing body image disturbance in adolescents (Campbell \& 
Hausenblaus, 2009; Neumark-Sztainer et al., 2004) but our findings extend the existing results because a short multilateral intervention caused sufficient physical and psychological changes to improve the perception of one's body by reducing dissatisfaction.

Our findings agree with previous studies that state that female body image dissatisfaction is generally associated with a desire for a thinner physique (Dion et al., 2016; Tiggemann, 2004). For girls, the desire to alter shape or weight during adolescence is common, and is associated with emotional distress, dramatic measures to alter appearance such as cosmetic surgery, depression, eating disorders (Bearman et al., 2006) and exercise addiction (Calogero, \& Pedrotty-Stump, 2010; Tarturo, Greco, Cataldi, \& Fischetti, 2016).

Before the implications of these findings are presented, it is necessary to discuss the possible limitations of the current investigation. Participants were recruited from a single high school on the basis of certain characteristics (e.g., age, same socio-economic background of origin and physical activity levels). Therefore, with a fairly homogenous population it is possible that adolescents of a similar age and with different characteristics would have responded differently to the multilateral training intervention undertaken in the present study. Thus, the positive effects noted in the present investigation, for body image dissatisfaction and body-size discrepancy between current and ideal self-perception, may not be observed in other populations.

\section{CONCLUSIONS}

In summary, the present research showed significant improvements in body mass, body image dissatisfaction and body-size perception in the female adolescents due to participation in 8 weeks of multilateral training. These findings highlight the role of specific activities performed through a multilateral approach consisted in exercises aimed to develop of the conditional and coordinative motor abilities besides team games. If one of the main objectives for physical educators is to promote healthy lifestyles and aid positive psychological health in children/adolescents, then extracurricular activities such as multilateral training should be considered.

\section{FUNDING}

No sources of funding were used to assist in the preparation of this manuscript.

\section{CONFLICT OF INTEREST STATEMENT}

The authors declared no potential conflicts of interest with respect to the research, authorship, and/or publication of this article.

\section{AUTHORS' CONTRIBUTIONS}

FL designed the study, collected and interpreted the data and wrote the manuscript. GG carried out the statistical analysis, interpreted the data, wrote and revised the manuscript. FF interpreted the data and revised the manuscript. SC designed the study, interpreted the data and wrote the manuscript. All authors contributed intellectually to the manuscript, and all authors have read the manuscript and approved the submission. 


\section{REFERENCES}

Austin, S. B., Haines, J., \& Veugelers, P. J. (2009). Body satisfaction and body weight: gender differences and sociodemographic determinants. BMC public health, 9(1), 313-319. https://doi.org/10.1186/1471-2458-9-313

Bearman, S. K., Presnell, K., Martinez, E., \& Stice, E. (2006). The skinny on body dissatisfaction: A longitudinal study of adolescent girls and boys. Journal of youth and adolescence, 35(2), 217-229. https://doi.org/10.1007/s10964-005-9010-9

Bompa, T.O. \& Buzzichelli, C.A. (2018). Periodization: Theory and Methodology of Training (6th ed.).Champaign, IL: Human Kinetics.

Burgess, G., Grogan, S., \& Burwitz, L. (2006). Effects of a 6-week aerobic dance intervention on body image and physical self-perceptions in adolescent girls. Body image, 3(1), 57-66. https://doi.org/10.1016/..bodyim.2005.10.005

Calogero, R. M., \& Pedrotty-Stump, K. N. (2010). Incorporating exercise into eating disorder treatment and recovery: Cultivating a mindful approach. In Treatment of Eating Disorders (pp. 425-441). Academic Press. https://doi.org/10.1016/b978-0-12-375668-8.10025-7

Campbell, A., \& Hausenblas, H. A. (2009). Effects of exercise interventions on body image: A metaanalysis. Journal of health psychology, 14(6), 780-793. https://doi.org/10.1177/1359105309338977

Catuzzo M.T., Henrique, R. S., Re' A.H.N., de Oliveira, I. S., Melo, B. M., Moura, M. S., Araujo, R.C., \& Stodden, D. (2016). Motor competence and health related physical fitness in youth: A systematic review. Journal of Science and Medicine in Sport, 19, 123-129. https://doi.org/10.1016/i.jsams.2014.12.004

Cohen, J. (1992). A power primer. Psychological bulletin, 112(1), 155.

Cohen, L., Manion, L., \& Morrison, K. (2011). Research Methods in Education (7th edition). Oxford, UK: Routledge.

Croll, J. (2005) Body image and adolescents. In: Stang. J. \& Story. M. (Eds.). Guidelines for adolescent nutrition services. Center for Leadership, Education, and Training in Maternal and Child Nutrition. Division of Epidemiology and Community Health. School of Public Health. University of Minnesota, Minneapolis, MN, USA, pp. 155-164. https://doi.org/10.1016/s1526-9523(01)00183-0

Crouter, S. E., Salas, C., \& Wiecha, J. (2016). Effects of an afterschool community center physical activity program on fitness and body composition in obese youth. Journal of Sports Sciences, 19, 1-7. https://doi.org/10.1080/02640414.2016.1209305

Cuzzolaro, M., Vetrone, G., Marano, G., \& Battacchi, M. W. (1999). BUT, Body Uneasiness Test: a new attitudinal body image scale. Psichiatria dell'infanzia e dell'adolescenza, 66, 417-428. https://doi.org/10.1037/t68647-000

Dion, J., Hains, J., Vachon, P., Plouffe, J., Laberge, L., Perron, M., ... \& Leone, M. (2016). Correlates of body dissatisfaction in children. The Journal of pediatrics, 171, 202-207. https://doi.org/10.1016/i.jpeds.2015.12.045

Dishman, R.K., Hales, D.P., Pfeiffer, K.A., Felton, G.A., Saunders, R., Ward, D.S., Dowda, M., \& Pate, R.R. (2006). Physical self-concept and self-esteem mediate cross-sectional relations of physical activity and sport participation with depression symptoms among adolescent girls. Health Psychology, 25(3), 396-407. https://doi.org/10.1037/0278-6133.25.3.396

Faul, F., Erdfelder, E., Lang, A. G., \& Buchner, A. (2007). G*Power 3: A flexible statistical power analysis program for the social, behavioral, and biomedical sciences. Behavior Research Methods, 39, 175191. https://doi.org/10.3758/bf03193146 
Fischetti, F., Cataldi, S., Di Terlizzi, P.G., \& Greco, G. (2019). Multilateral methodology in physical education improves coping skills, resilience and physical fitness in drug addicts. Journal of Human Sport and Exercise. https://doi.org/10.14198/ihse.2020.152.11

Fischetti, F., \& Greco, G. (2017). Multilateral methods in Physical Education improve physical capacity and motor skills performance of the youth. Journal of Physical Education and Sport, 17(Suppl 4), 2161-2168. https://doi.org/10.7752/jpes.2017.s4223

Fischetti, F., Cataldi, S., \& Greco, G. (2019). A Combined Plyometric and Resistance Training Program Improves Fitness Performance in 12 to 14-years-old Boys. Sport Sciences for Health. https://doi.org/10.1007/s11332-019-00560-2

Fischetti, F., Latino, F., Cataldi, S., \& Greco, G. (2019). Gender Differences in Body Image Dissatisfaction: The Role of Physical Education and Sport. Journal of Human Sport and Exercise. https://doi.org/10.14198/ihse.2020.152.01

Graham, M.A., Eich, C., Kephart, B., \& Peterson, D. (2000). Relationship among body image, sex, and popularity of high school students. Perceptual \& Motor Skills, 90(3 Pt 2),1187-1193. https://doi.org/10.2466/pms.2000.90.3c.1187

Greco, G., Cataldi, S., \& Fischetti, F. (2019). Effectiveness of a Short After-School Intervention on Physical Fitness in School-Aged Children. Journal of Theories and Research in Education.14(1), 143-164. https://doi.org/10.6092/issn.1970-2221/9217

Greco, G., Settimo, M., \& Fischetti, F. (2018). Relationship between the correct running technique and lower back well-being perceived by the practitioner. Journal of Physical Education and Sport,18(3), 1796-1800. https://doi.org/10.7752/jpes.2018.03262

Hardy, L.L., King, L., Espinel, P., Cosgrove, C., \& Bauman, A. (2010). NSW Schools Physical Activity and Nutrition Survey (SPANS): Full Report. NSW Ministry of Health, Sydney. Retrieved from http://www.health.nsw.gov.au/heal/Publications/spans-2015-full-report.PDF

Henry, R. N., Anshel, M. H., \& Michael, T. (2006). Effects of aerobic and circuit training on fitness and body image among women. Journal of Sport Behavior, 29(4), 281-303.

Jaffee, L., \& Mahle Lutter, J. (1995). Adolescent Girls: Factors Influencing Low and High Body Image. Melpomene Journal, 14(2), 14-22.

Kostanski, M., Fisher, A., \& Gullone, E. (2004). Current conceptualisation of body image dissatisfaction: have we got it wrong? Journal of child Psychology and Psychiatry, 45(7), 1317-1325. https://doi.org/10.1111/j.1469-7610.2004.00315.x

Lawler, M., \& Nixon, E. (2011). Body dissatisfaction among adolescent boys and girls: the effects of body mass, peer appearance culture and internalization of appearance ideals. Journal of youth and adolescence, 40(1), 59-71. https://doi.org/10.1007/s10964-009-9500-2

Li, X. H., Lin, S., Guo, H., Huang, Y., Wu, L., Zhang, Z.,...Wang, H. J. (2014). Effectiveness of a schoolbased physical activity intervention on obesity in school children: A nonrandomized controlled trial. BMC Public Health, 14, 1282. https://doi.org/10.1186/1471-2458-14-1282

Lubans, D. R., Morgan, P. J., Cliff, D. P., Barnett, L. M., \& Okely, A.D. (2010). Fundamental movement skills in children and adolescents. Review of associated health benefits. Sport Medicine, 40(129), 1019-1035. https://doi.org/10.2165/11536850-000000000-00000

Mäkinen, M., Puukko-Viertomies, L. R., Lindberg, N., Siimes, M. A., \& Aalberg, V. (2012). Body dissatisfaction and body mass in girls and boys transitioning from early to mid-adolescence: additional role of self-esteem and eating habits. BMC psychiatry, 12(1), 35-42. https://doi.org/10.1186/1471-244x-12-35

Mears, R., \& Jago, R. (2016). Effectiveness of after-school interventions at increasing moderate-tovigorous physical activity levels in 5- to 18-year olds: A systematic review and meta-analysis. British Journal of Sports Medicine, 50(21), 1315-1324. https://doi.org/10.1136/bjsports-2015-094976 
Neumark-Sztainer, D., Goeden, C., Story, M., \& Wall, M. (2004). Associations between body satisfaction and physical activity in adolescents: Implications for programs aimed at preventing a broad spectrum of weight-related disorders. Eating Disorders, 12(2), 125-137. https://doi.org/10.1080/10640260490444989

O'Brien, J., Ginis, K. A. M., \& Kirk, D. (2008). The effects of a body-focused physical and health education module on self-objectification and social physique anxiety in Irish girls. Journal of Teaching in Physical Education, 27(1), 116-126. https://doi.org/10.1123/itpe.27.1.116

O'Donovan, T., \& Kirk, D. (2008). Reconceptualizing student motivation in physical education: An examination of what resources are valued by pre-adolescent girls in contemporary society. European Physical Education Review, 14(1), 71-91. https://doi.org/10.1177/1356336x07085710

Parsons, E. M., \& Betz, N. E. (2001). The relationship of participation in sports and physical activity to body objectification, instrumentality, and locus of control among young women. Psychology of Women Quarterly, 25(3), 209-222. https://doi.org/10.1111/1471-6402.00022

Presnell, K., Bearman, S. K., \& Stice, E. (2004). Risk factors for body dissatisfaction in adolescent boys and girls: A prospective study. International Journal of eating disorders, 36(4), 389-401. https://doi.org/10.1002/eat.20045

Ruble, D.N., Martin, C.L., Berenbaum, S.A. (2006). Gender development. In: Damon, W., et al. (Eds.), Handbook of child psychology. Social, emotional and personality development (6th ed.). Hoboken, New Jersey, USA: John Wiley and Sons, pp. 858-932.

Russ, L. B., Webster, C. A., Beets, M. W., \& Phillips, D. S. (2015). Systematic review and meta-analysis of multi-component interventions through schools to increase physical activity. Journal of Physical Activity and Health, 12(10), 1436-1446. https://doi.org/10.1123/jpah.2014-0244

Sallis, J.F. (2000). Age-related decline in physical activity: a synthesis of human and animal studies. Medicine \& Science in Sports \& Exercise, 32, 1598-1600. https://doi.org/10.1097/00005768$\underline{200009000-00012}$

Tarturo, A., Greco, G., Cataldi, S., \& Fischetti, F. (2016). Body image, anxiety and eating disorders in sprinters athletes. Sport Sciences for Health, 12(suppl 1), S1-S94. https://doi.org/10.1007/s11332$\underline{016-0305-x}$

Thompson, M.A., \& Gray, J. (1995). Development and validation of a new body-image assessment scale. Journal of Personality Assessment, 64, 258-269. https://doi.org/10.1207/s15327752jpa6402_6

Tiggemann, M. (2004). Body image across the adult life span: Stability and change. Body image, 1(1), 29-41. https://doi.org/10.1016/s1740-1445(03)00002-0

Van Sluijs, E. M., McMinn, A. M., \& Griffin, S. J. (2007). Effectiveness of interventions to promote physical activity in children and adolescents: Systematic review of controlled trials. BMJ, 335, 703. https://doi.org/10.1136/bmi.39320.843947.be

Wertheim, E. H., Paxton, S. J., \& Tilgner, L. (2004). Test-retest reliability and construct validity of Contour Drawing Rating Scale scores in a sample of early adolescent girls. Body Image, 1(2), 199-205. https://doi.org/10.1016/s1740-1445(03)00024-x

Wertheim, E.H., \& Paxton, S.J. (2011). Body image development in adolescent girls. In: Cash, T., Smolak, L. (Eds.), Body image: A handbook of science, practices and prevention (2nd ed.). New York, NY, USA: The Guilford Press, pp. 76-84. https://doi.org/10.1037/11860-003

\section{(9) $(\mathbb{Q} \Theta \Theta$}

This work is licensed under a Attribution-NonCommercial-NoDerivatives 4.0 International (CC BY-NC-ND 4.0). 